\title{
Perceived Self-Efficacy and Its Relationship to Achievement Motivation among Parallel Program Students at Prince Sattam University
}

\author{
Ahmad H. Harahsheh ${ }^{1}$ \\ ${ }^{1}$ College of Education-Dilam, Prince Sattam Bin Abdul Aziz University, Alkharj, Kingdom of Saudi Arabia \\ Correspondence: Ahmad H. Harahsheh, College of Education-Dilam, Prince Sattam Bin Abdul Aziz University, \\ Alkharj, Kingdom of Saudi Arabia. E-mail: ahmadhm2004@yahoo.com
}

Received: June 9, 2017

Accepted: June 21, 2017

Online Published: June 28, 2017

doi:10.5539/ijps.v9n3p21

URL: http://doi.org/10.5539/ijps.v9n3p21

\begin{abstract}
The study aimed to identify the level of perceived self-efficacy and achievement motivation and the relationship between them. The sample of the study included 164 students. The researcher used the measure of perceived self-efficacy and the measure of achievement motivation. The measure of perceived self-efficacy consisted of 72 paragraphs distributed on nine dimensions. While the measure of achievement motivation consisted of 20 paragraphs. It has been conducted the necessary honesty and reliability coefficients for them.

The results indicated to the high levels of perceived self-efficacy and achievement motivation, to a correlation which is very weak and a positive direction (proportional) with statistical significance between perceived self-efficacy dimension (behavioral) and achievement motivation, to six correlation relationships which are weak and a positive direction (proportional) with statistical significance between perceived self-efficacy dimensions (emotional, social, self-confidence, others-confidence, cognitive, moral) and achievement motivation, to the presence of correlation relationship which is medium and positive direction (proportional) with statistical significance at the significance level $(\alpha=0.05)$ between perceived self-efficacy and its two dimensions (persistence and perseverance, academic) and achievement motivate.
\end{abstract}

Keywords: self-efficacy, achievement motivation, parallel program students

\section{Introduction}

The perceived self-efficacy contribute to identify the behavior of the initiative for the individual, and determine the degree of achievement motivation, the degree of perseverance to achieve a particular work. The realization of student to his/her self-efficacy effects on his/her ability. The student who is characterized by high self-efficacy tends to self-learning and achievement compared to student with low self-efficacy, that means, when the actual capacity is equal between the two parties, the student has the ability not only to do work, but also to accomplish work successfully.

The concept of self-efficacy appeared by (Bandura) in article "efficiency or self-efficacy toward a single theory of behavior modification" and then he linked to the concept of self-control of behavior in his theory and developed the idea of owning individual beliefs allowing them to adjust their thoughts, feelings and actions. This adjustment represents the normative framework of behavior in terms of level and content (Bandura, 1986). Many modern theories assert on the self-importance and the individual perceptions for himself, which influence in the construction of the individual's personality (Harte, 1983; Zahran, 2003).

Bandura and Wood (1989) see that the perceived self-efficiency influences in the pattern of thinking and behavior, it may be a self-assistances, or self-constraints. Students who are too sensitive to self-efficiency center their thinking and behavior on analyzing the problems and trying to find appropriate solutions. While the students who are less sensitive to self-efficiency center in their thinking to the inside, and drown themselves worries when faced certain problems; therefore, they have tension and lack of behavior control, and feel of helplessness and anxiety in cognitive abilities and a failure to employ them in the decision making.

Shunk (1986) indicated to the possibility to make use of perceived self-efficiency to learn cognitive tasks, so he supposed that the orientation and the enthusiasm of students to learn vary in the degree of their trust and their 
belief in their ability to learn the present course, and their abilities vary to implement the skills that contribute to the development of their knowledge and affect to the ability on the cognitive processing of the learning process, and understand the reasons of the real success and failure which the students have. He believed that the motivation of the students to demand or avoid the educational activities refers to their impression of their perceived self-efficiency, or to the reward associated with completing the task successfully, and the behavior related to motivation helps to learn, and develops a positive achievement motivation.

Hence, the concept of achievement motivation helps to explain the individual differences in academic achievement when he attributed the differences to the non-intelligent factors and academic preparation. Many of the students who have the medium mental abilities characterize by the high academic collection, compared with others who have the high mental abilities and they get a low academic collection; factor here is high and low achievement motivation in the effort and willingness (Abu Allam, 2004).

\subsection{Problem of the Study}

Our contemporary time flourishes a lot of intellectual and scientific development and social change, and all these developments link to the ability of individuals to absorb and employ them to achieve the required growth in various fields of life; therefore it is necessary to study their self-efficiency and their achievement motivation to optimally employ them to achieve success and encounter the rapid developments in the various aspects of the lives of individuals. It is no doubt that the lack of awareness of individuals to their self-efficiency, and knowledge of their willingness to accomplish and link these two variables to achieve success, leading them to psychological and social pressures and unrests which hinder their progress in life in terms of study, work and family.

It is therefore important to examine the perceived self-efficacy and achievement motivation, activate their role in the educational and social fields, and work to put the effective programs to raise the degree of self-efficacy and achievement motivation for them due to they contribute to achieving success and compatibility with various aspects of life.

\subsection{Objectives and Questions of the Study}

This study aims to identify the perceived self-efficacy, and achievement motivation, and the nature of their relationship for the students of the study (parallel system) at Prince Sattam Bin Abdul-Aziz University in Saudi Arabia. Specifically to answer the following questions:

1) "What is the perceived self-efficacy level for students of the parallel system at Prince Sattam Bin Abdul-Aziz University?"

2) "What is the level of the achievement motivation for the students of the parallel system at Prince Sattam Bin Abdul-Aziz University?"

3) "Is there a statistically significant correlation at the significance level $\alpha=0.05$ between the perceived self-efficacy and the achievement motivation for students of the parallel system at Prince Sattam Bin Abdul-Aziz University?"

\subsection{Significance of the Study}

The significance of the study investigates the level of the perceived self-efficacy and its relationship with the achievement motivation for the students of the study (parallel system) in Prince Sattam Bin Abdul-Aziz University. Universities and their students are beacons of science, development and adoption of educational policies, and put plans and future educational programs contribute to raising the level of achievement motivation and self-efficacy of the students, where the students are the future leaders and elements of fulfilling achievement and the superiority of society in various fields of life.

The significance of the study lies in that the perception of student to his/her self-efficacy; is considered a preventive treatment for many disorders as disappointment, anxiety and fear of failure, by adopting a positive self-control center of the behavior. It will also stimulate further studies working to develop guiding programs which raise the level of self-efficacy and achievement motivation of the participants.

Study limitations: the results of this study are determined by students of Prince Sattam in Abdul-Aziz University who study parallel system and register in the second semester of the academic year 2016/2017 A.B. 


\subsection{The Theoretical Framework and Previous Studies}

\subsubsection{The Concept of Perceived Self-Efficacy: Sources, Forms and Importance}

The Perceived self-efficacy is known as an individual's belief of his/her self-potential and confidence in his/her ability and his/her knowledge, and he/she has the mental, cognitive, emotional, sensory and nervous competences being able to achieve an acceptable level and a balance, determine efforts and energies at this level (Pajares, 1999).

Bandura (1987) indicates that the perception of the individual to his/her self-efficacy associated to evaluate his/her abilities and control events to achieve a certain level of achievement, so the control of the event affect the level of self-efficacy, the nature of work and the goal, the amount of required effort, the way of thinking, and the amount of tension that face in adapting to the potential environmental demands.

The theoretical literature points to the possibility of the development of the perceived self-efficacy, and learns the concepts, autovalorisation, and the general psychological adaptation through educational attitudes and achievement. Thus, the individual is not compelled from the others and the environment and that his/her actions and behaviors directed from out and if they lead to positive results, they won't elevate the level of self-efficacy to do the expected behaviors in the future (Deci, 1989).

The sense of an individual to possess the ability to adjust the behaviors, thoughts and feelings is one of the most important indicators of successfully psychological and social adaptation. In the case of one's awareness that he/she has the ability to adjust the behaviors and thoughts, he/she becomes more capable of dealing with the pressure and forming the good relationships with others; so the beliefs and expectations are considered a component of the personality and involve the conviction and the self-ability to control and to overcome the problems. This configuration of the character affects the individual's attitudes, self-knowledge and ability to perform behavior that fulfills achievement (Madux \& Lewis, 1995; Zahran, 2003).

Bandura determines the sources of the perceived self-efficacy by direct experiences: where success in a particular task leads to success and increase it. He also points to the source of indirect experiences: the alternative experiences, seeing people succeed in performing a work leads to raise the perceived self-efficacy and noting another who has the same efficiency and fails in the same work leads to lower the perceived self-efficacy for him/her; and this means that he/she encodes the behavior of others. There is another source which is the symbolic experiences representing in the ability the credible and trustworthy person to convince another to be able to do the desirable behavior. There is a source of emotional experiences: the physical and emotional excitement impacts on self-efficacy of the individual. The source of the self-assessment attribute the individuals outputs of their work to a personal internal reasons, the positive self-assessment works to promote autoimmune responses, as well as a source of ambient conditions which may negatively or positively reinforce expectations (Hamdi \& Dawood, 2000).

With regard to forms of the perceived self-efficacy, there is a set of beliefs and interactive perceptions which produce jobs linked to self-control of the thinking processes, the motivation and the emotional and physiological fields represented in the following forms: (1) The general form: the individual's belief and awareness of his/her abilities to perform in various conditions and the level of difficulty of the task. (2) Social form: the belief and the awareness of the individual within a particular social framework ranging from the simple to the complex. (3) Academic form: it means a belief and awareness of the individual's abilities and capacities in various academic fields and levels during the life stages (Azzyat, 2001).

With regard to the importance of perceived self-efficacy, social learning theory clears that it affects the pattern of thinking. Whenever the self-efficiency increases, the power and control of emotion and behavior will raise. Therefore, whoever owns the high self-efficiency has a high ability to encounter the behavioral, educational, social, emotional and moral problems, is characterized by rationality and boldness without adventure or disrespect, has the determination and endurance, and will be less tense and more balanced than the emotive and emotional. Thus, the concept of the perceived self-efficacy is motives towards achieving success in the event of successful experiences, leading to failure in light of frustrating experiences. The concept of perceived self-efficacy can be also developed by comparing the abilities, potentials, preparations of the individual to the others. Students who own of the academic perceived self-efficacy have a high ability to organize themselves, perform jobs that require extra effort, and subject to less level of disturbance (Azzyat, 2001).

Social learning theory believes that belief of perceived self-efficacy impacts on behavior in four areas: first, choosing behavior: It shows students' orientation to do tasks that give them a high ability on competition and achievement, hence the student's perceived self-efficacy determines his/her behavior. Second, the amount and 
average of an effort, a student who believes that he has a high self-efficacy is keen to persevere in the performance and prediction of activity, and makes a greater effort to achieve high attainment. The third area is this: the pattern of thinking and reaction, the student who believes strength of the perceived self-efficacy links between the act and the result attributes the failure of a difficult task to a lack and insufficiency of the effort, while the student who has low sense attributes that failure to lack of ability he has. Fourth: the individual produces a behavior: where the high confidence generates the success and leads to a better level of performance, and its weakness breeds hesitation and avoids try; to avoid failure (Bandura, 1986). Studies indicate that there is a relationship between the perceived self-efficacy, perseverance and success among the students of university. The students with the high self-efficacy of academic requirements receive the highest grades in the attainment, and persist for long time, so the students' awareness of self-efficacy affect the plans prepared in advance; they positively plan to achieve success compared to other (Lent, Brown, \& Larkin, 1984).

\subsubsection{The Concept and Significance of Achievement Motivation}

Murray introduces the concept of motivation of achievement which means to overcome the difficulties, strive to satisfactorily accomplish difficult work, achieve a high level of excellence and compete with others. The achievement motivation is a motive acquired of the individual's experience and interaction with the surrounding environment and it influences by factors such as: cultural values, social role of individuals, educational processes in the education system, the interaction between the group, and methods of socialization where the family develop through support, reinforcement and opportunity for competition between individuals. It also links the achievement motivation to the behavior of the individual where much of the individuals' behavior can be explained according to their motives.

Achievement motivation associates with learning and represents a feeling of joy after the completion of a particular task by a distinctive manner, and its importance lies in a sustained effort to succeed in the study and the work and reflects the desire for performance superiorly. The term "Motive" indicates to the internal conditions stimulating the individual to fill the deficiency or biological, psychological or social need; so it is linked to the need, and the need involves to decrease or increase in the case of an individual and causes tension and anxiety; thus, motive works to remove them and restore the individual to the equilibrium case with the internal and external environment (Nashawati, 2003).

The achievement motivation considers a developmental phenomenon which obviously increases by developing the life. Individuals differ in their quest toward accomplishing the achievement. Some of them seek to it for reaching to the achievement and the success and others for avoiding failure and anxiety associated with the lack of achievement. The individuals with the high achievement motivation are characterized by special characteristics including: discrimination, decision-making and personal responsibility, setting goals carefully, and independence, enthusiasm, ambition, perseverance and self-confidence (Hassan, 1998).

Motives can be divided into two parts: (1) the initial motives: result from the organic and physiological needs of the body, such as food and sex, and the failure of needs' satisfaction cause the tension. This is why the individual resorts to the activity and does something to restore equilibrium. (2) Secondary motives: are social psychological motives associated with the individual's relationships with others. Including possession motive, self-assertion, belonging, and social acceptance and the individual motives including the achievement motivation which differs from one individual to another; and this difference is due to the variation in the level of motivation.

Smith indicates to two kinds of the achievement motivation according to comparing the individual himself to others, namely:

1) The autonomous achievement Motivation: includes an application of internal personal standards, and the absolute standards of achievement in a particular situation.

2) The social achievement motivation: includes application of standards of excellence on social comparison in the situation. Ozibil has determined the components of achievement motive into three components:

(1) Cognitive motive: is a satisfaction of the needs of cognition and understanding.

(2) Self-direction: is the individual's desire to prestige and a sense of self-respect through outstanding performance.

(3) Belonging motive: represents the desire for an acceptance from others who are important his/her life (Khalifa, 2000).

The relationship between the perceived self-efficacy and the achievement motivation appears by considering the perceived self-efficacy as a cognitive mediator of the behavior. Individuals determine their behavior, the effort 
that they exert, the degree of perseverance in encountering their problems, the behavior of the initiative and perseverance which they have, and their competence to successfully deal with the surrounding circumstances and challenges based on their expectations of their perceived self-efficacy; therefore, efficiency determines individuals' realization for the task as an opportunity or a threat; consequently, they are either to do the work, or to reject it. It is the motive to achievement and attainment ((Maddux \& Lewis, 1995).

The individual's beliefs of the perceived self-efficacy organize his/her practical plans required for the achievement, achieve the goal, and also affect the behavior and energy in encountering the challenges to coincide with the level of actual achievement of the individual. So this study explores the relationship between the perceived self-efficacy and achievement motivation for the students of parallel system at Prince Sattam Bin Abdul-Aziz University to encourage the implement of programs that develop the perceived self-efficacy for them, to improve their behavioral, cognitive, emotional beliefs, and to rise the degree of motivation for achievement and success.

In a review of previous studies, Bandura and Wood (1989) conduct a study which aims to reveal the relationship between the achievement and the ability to decision-making and the perceived self-efficacy the two sexes. The sample of the study consists of 173 students from the graduate students. The results indicate that the high self-efficacy improved the ability to decision-making and achievement, while the low self-efficacy leads to a low level of the ability to decision-making and achievement. Also, there are statistically significant differences in the level of self-efficacy between the two sexes in favor of males.

Landine and Stewart (1998) conduct a study aims to reveal the relationship between the abilities of metacognition, motivation, center of control, perceived self-efficacy, and academic attainment. The sample of the study consists of 108 students of the level of the twelfth grade. After responding to the study tools which include a tool for measuring the self-efficacy, the results indicate to a strong positive relationship between the perceived self-efficacy and the academic attainment.

The sample of Hanover's study (2000) consists of 187 students at the university level. The researcher uses Harter tool of the self-efficiency. It aims to reveal the role of sex in the development of the self-efficacy. The results indicate that the examined sex has a role in the development of self-efficacy, and that the difference between males and females during the time refers to the differences of self-characteristics and behaviors.

Hamdi's and Dawood's study (2000) aims to reveal the relationship of the self-efficacy of the sex variables and the degree of depression and stress. The sample of the study consists of 414 students from the University of Jordan. The researchers have used a tool of self-efficacy and stress tool. The results indicate that there are statistically significant differences between the averages of male and female students in the total degree on self-efficiency tool, and there are the differences in the emotional and cognitive dimensions in favor of males. The results also show the statistically significant differences among the students who have the low and high stress in the total degree on the self-efficiency tool, and the significant differences the behavioral, cognitive and emotional dimensions in favor of students who have the low stress.

Assaqer's study (2005) aims to reveal the level of moral growth, the perceived self-efficacy and their relationship according to the sample of the study which consists of 654 students from Yarmouk University. The researcher uses the tool of the moral development for (Rist) on the Jordanian environment and the tool of the perceived self-efficacy that the researcher conducts. The results indicate that the significant differences in the level of the perceived self-efficacy point to the sex variable in favor of males, the statistically significant differences in the level of the perceived self-refer to the academic variable, there are not the significant differences in the level of the perceived self-efficacy due to the specialization variable, and the existence of the statistically significant relationship between the moral growth and the level of the perceived self-efficacy.

In a review of studies that deal with the achievement motivation, Ammar has conducted (1987) study aimed to identify the differences in the achievement motivation among the Tunisian university students according to the variables of specialization (psychology and philosophy) and sex. The sample of the study consists of 79 students of psychology and 94 students of philosophy. The researcher has used the test (Hermans, 1970) to the achievement motivation for adults. The results show that there are not differences in the level of achievement motivation due to the variables of the study.

The Attawwab (1990) conducts a study which aims to reveal the nature of the relationship between the achievement motivation and intelligence and the academic attainment for the students in the United Arab Emirates University. The sample of the study consists of 60 male and 80 female students. The results show the presence of a statistically significant difference in academic attainment attributed to the high achievement 
motivation, while the results do not show the existence of differences between the students in achievement motivation and intelligence.

Ababneh's study (1999) aims to identify the impact of personal characteristics on the level of the achievement motivation for the students of the Yarmouk University. The sample of the study consists of 746 students who are chosen a stratified random way. The results indicate that there is not a statistically significant impact on the level of achievement motivation due to sex variable and college and university stage, and point to the presence of a statistically significant relationship between achievement motivation and six of the personal factors for Participants.

\section{The Methods and Procedures}

The methods and the procedures discuss a description of the method and society and sample of the study, the tools that are used, and its validity and reliability, and identify the variables, statistical treatments, and procedures of the study that are used to answer its questions.

\subsection{Method}

Correlative descriptive method is used to identify on the level of the perceived self-efficacy, the level of the achievement motivation, and their relationship for the students of the parallel system at Prince Sattam Bin Abdul-Aziz University, due to its relevance with the nature of this study and its objectives.

\subsection{The Study Society}

The study society consists of all students of the parallel system at Prince Sattam Bin Abdul-Aziz University, and registered students in the second semester of the academic year 2016/2017 A.D.

\subsection{Sample of the Study}

The sample of the study consists of 164 students who answered the study tools and took back by 63 male and 101 female students.

\subsection{Study Tools}

The study includes two tools; namely: 1) The perceived self-efficacy tool. 2) The achievement motivation tool. The researcher prepares the tools by reviewing the theoretical literature and the previous studies related to the perceived self-efficacy including: Landine and Stewart (1998); Hanover (2000); Hamdi and Dawood (2000); Assaqer (2005). The tool consists of 72 items distributed on the nine dimensions. The previous studies related to the achievement motivation tool are reviewed, including: Ammar (1987); Attawwab (1990); Ababneh (1999). The tool consists of 20 items. The researcher uses the quinary gradation of the two tools which are checked the veracity of them, introduced by a group of specialists, and carried out them the necessary honesty and reliability.

\subsubsection{Significances of Constructing Reliability of Study Tools}

The two tools are applied on a prospective sample of 15 students outside the target study sample to calculate Pearson's correlation coefficients between the specific items on the perceived self-efficacy and the tool and the dimensions that follow them, and to calculate Pearson's correlation coefficients to items of the achievement motivation and the tool as a whole. It is Noted from the values of honest construction the correlation coefficient of each item of the perceived self-efficacy tool with the tool and its dimensions, and that the correlation coefficient of each paragraph of the achievement motivation tool with the tool is not fewer than the standard (0.20); which refers to the quality of construction of the items of the study tools. In addition to the foregoing; the correlation coefficients of dimensions of the perceived self-efficacy tool are calculated with the tool as a whole, as well as the interfacial correlation. In addition to the foregoing; the correlation coefficients of dimensions of the perceived self-efficacy tool are calculated with the tool as a whole, as well as the interfacial correlation coefficients for the dimensions of the tool are calculated, by using the Pearson's correlation coefficient ranging from 0.62 until 0.79 , and the values of the interfacial correlation coefficients for the dimensions of the tool has ranged from .18 and until 0.55 . 


\subsubsection{Significances of the Stability of Study Tools}

To achieving the stability of the internal consistency of the perceived self-efficacy tool and its dimensions, and the achievement motivation tool; it has been calculated by using Cronbach's Alpha equation on the first application data of a prospective sample. To achieving the stability of returning the study tools; it has been reapplied on the prospective sample by the Test and Retest during two weeks between the first and the second applications, which it is calculated by using the Pearson's correlation coefficient between the first and second applications on the prospective sample, where the stability of the internal consistency of the perceived self-efficacy tool has reached to the value 0.90 and its dimensions ranging from 0.79 until 0.85 , while the stability of returning the tool may reach to 0.84 and its dimensions ranging from 0.80 until 0.89 . With regard to the achievement motivation tool, its value of the stability of the internal consistency reaches to 0.90 , and the value of the stability of returning the tool reaches to 0.81 .

\subsection{Standard of Correcting the Study Tools}

The adoption of a statistical pattern of absolute gradation is in order to issue the controls the arithmetic averages of the dimensions, items, and tools of the study, as the following:

The level of perceived self-efficacy category of the arithmetic averages

The level of achievement motivation High Median category of the arithmetic averages more than 3.49 2.50 to 3.49

Low

less than 2.50

\subsection{The Study Variables}

The study includes the following variables: Dependent variables; namely: 1) The perceived self-efficacy and dimensions that follow it. 2) The achievement motivation.

\subsection{Statistical Treatments}

In this study, the statistical treatments of the data by using the Statistical Package for Social Sciences (SPSS) are as the following:

1) To answer the first two questions of the study; the arithmetic averages and the standard deviations of the perceived self-efficacy and dimensions that follow it, and the items that follow the dimensions are calculated, and the arithmetic averages and the standard deviations of the achievement motivation and the items that follow it for participants are calculated, taking into account the order of the items in descending order according to their arithmetic averages.

2) To answer the third question of the study; the Pearson's correlation coefficients between the perceived self-efficacy and its dimensions are calculated on the one hand and between the achievement motivation in the other hand.

\section{Discussing the Results and Recommendations}

The study aimed to reveal the level of the perceived self-efficacy and the level of achievement motivation and the relationship between them for students of the parallel system at Prince Sattam Bin Abdul-Aziz University, specifically to answer the following questions of the study:

3.1 Results Related to Question of the Study, Which Stated: "What Is the Level of the Perceived Self-Efficacy for Students of the Parallel System at Prince Sattam Bin Abdul-Aziz University?"

To answer the first question of the study; the arithmetic averages and the standard deviations of the perceived self-efficacy and dimensions for the participants, taking into account the of the descending or according order of the dimensions to their arithmetic averages, as in Table 1. 
Table 1. The arithmetic averages and standard deviations of the perceived self-efficacy and its dimensions for the participants in descending order

\begin{tabular}{|c|c|c|c|c|c|}
\hline Rank & No. of dimension & Perceived self-efficacy and its dimensions & Arithmetic average & standard deviations & Level \\
\hline 1 & 9 & Moral & 4.20 & 0.50 & High \\
\hline 2 & 2 & Social & 4.15 & 0.52 & High \\
\hline 3 & 5 & Confidence of the Other & 4.02 & 0.53 & High \\
\hline 4 & 6 & Determination and Perseverance & 3.96 & 0.58 & High \\
\hline 5 & 1 & Emotional & 3.88 & 0.51 & High \\
\hline 6 & 3 & Behavioral & 3.84 & 0.55 & High \\
\hline 7 & 4 & Self-Confidence & 3.81 & 0.45 & High \\
\hline 8 & 8 & Academic & 3.66 & 0.62 & High \\
\hline 9 & 7 & Cognitive & 3.50 & 0.51 & High \\
\hline Macro-scale & & & 3.89 & 0.36 & High \\
\hline
\end{tabular}

The Table 1 shows that the level of the perceived self-efficacy and its dimensions for participants is (high) in according to the standard mentioned in the method and procedures, where the dimensions of the perceived self-efficacy are ordered according to the following: First, the moral dimension. Second, the social dimension. Third: dimension of confidence of the other. Fourth, determination and perseverance dimension. Fifth, emotional dimension. Sixth, behavioral dimension. Seventh, self-confidence dimension. Eighth, the academic dimension. Ninth, cognitive dimension.

The arithmetic averages and standard deviations are calculated to the items of the perceived self-efficacy dimensions, taking into consideration the order of the items within every dimension of the perceived self-efficacy in descending order according to their arithmetic averages, as illustrating in Appendix B. Occupying the moral dimension of the first rank can be explained that the participants belong to a society and a culture that are committed to the teaching of the religion; that religion is good moral, and the sample of the participants are old people who have a long experience of the life; so they are more committed to the principles and morals.

The high level of efficiency can also be attributed that the self-realization process passes in the extensive experience contributing to decision-making, and working on the composition of positive trends for abilities and capabilities to help in encountering events and taking the appropriate attitude.

3.2 Results Related to the Question of the Study, Which Stated: "What Is the Level of the Achievement Motivation for Students of the Parallel System at Prince Sattam Bin Abdul-Aziz University?"

To answer the second question of the study; the arithmetic averages and standard deviations for achievement motivation and the items that follow them for the participants, taking into consideration the order of the items in descending order according to their arithmetic averages, as in the Table 2. 
Table 2. Arithmetic averages, standard deviations of achievement motivation and the items that follow it for the participants in descending order

\begin{tabular}{|c|c|c|c|c|c|}
\hline Rank & No. of item & Achievement motivation & Arithmetic average & standard deviations & Level \\
\hline 1 & 4 & I feel happy when I put the goal and trying to achieve & 4.55 & 0.80 & High \\
\hline 2 & 20 & I trust my abilities to achieve success & 4.55 & 0.70 & High \\
\hline 3 & 1 & I try hard to achieve my ambitions & 4.43 & 0.81 & High \\
\hline 4 & 19 & I try hard to achieve the success to get a respect & 4.38 & 0.79 & High \\
\hline 5 & 9 & I pursue to be excellent in my university & 4.34 & 0.85 & High \\
\hline 6 & 7 & I pursue to achieve future plans which I put & 4.15 & 0.99 & High \\
\hline 7 & 16 & I achieve the required works correctly & 4.08 & 0.87 & High \\
\hline 8 & 8 & I bear the academic problems which I encounter & 3.99 & 0.98 & High \\
\hline 9 & 3 & $\begin{array}{l}\text { I have a great ability for patience to achieve a } \\
\text { particular work }\end{array}$ & 3.99 & 0.92 & High \\
\hline 10 & 14 & $\begin{array}{l}\text { I have determination and endurance to win the } \\
\text { competition }\end{array}$ & 3.91 & 1.09 & High \\
\hline 11 & 2 & I perfectly achieve my academic works & 3.87 & 0.89 & High \\
\hline 12 & 15 & $\begin{array}{l}\text { I work overtime to complete the work which I'm } \\
\text { required }\end{array}$ & 3.76 & 1.13 & High \\
\hline 13 & 12 & I prefer the works that need to high skills & 3.74 & 1.12 & High \\
\hline 14 & 10 & I perform my duties on the time & 3.74 & 1.08 & High \\
\hline 15 & 17 & I challenge others in achieving any work & 3.73 & 1.05 & High \\
\hline 16 & 18 & I perform my duties better than my classmates & 3.69 & 0.99 & High \\
\hline 17 & 13 & I try to accomplish tasks that are difficult & 3.46 & 1.11 & Median \\
\hline 18 & 11 & $\begin{array}{l}\text { I interest in knowing the details of the life of the } \\
\text { excellent people }\end{array}$ & 3.40 & 1.31 & Median \\
\hline 19 & 6 & $\begin{array}{l}\text { I enjoy in achieving my duties though it takes a long } \\
\text { time }\end{array}$ & 3.22 & 1.21 & Median \\
\hline 20 & 5 & I participate in academic competitions & 2.79 & 1.37 & Median \\
\hline Macro-scale & & & 3.89 & 0.60 & High \\
\hline
\end{tabular}

The Table 2 shows that the level of the achievement motivation for the participants is (high) according to the standard mentioned in the method and procedures, where the items are classified within the levels of achievement motivation; namely: (high) to the items with ranks from1 until 16, and (median) to the items with ranks of 17 to 20. This explains that a student feels happy when he/she puts the goal and seeks to achieve, and that when he/she is confident of his/her ability to be closer to achieving success. Success usually leads to get the respect of the people.

The participants who get less perseverance in achieving the difficult task, interest in the details of the life of the excellent people, enjoy to do the duties that require a long time, and share in the university competitions return to their preoccupation with their families and their work alongside their study, and their ages distract from tracking the life of the excellent people relying on their life experience.

3.3 Results Related to the Question of the Study, Which Stated: "Is There a Is a statistically Significant Correlation at the Significance Level $\alpha=0.05$ between the Perceived Self-Efficacy and the Achievement Motivation for Students of the Parallel System at Prince Sattam Bin Abdul-Aziz University?"

To answer the third question of the study; Pearson's correlation coefficients are calculated between the perceived self-efficacy and its dimensions on the one hand and the achievement motivation on the other hand for the participants, as in Table 3. 
Table 3. The values of the correlation coefficients between the perceived self-efficacy and its dimensions on the one hand and between the achievement motivation on the other hand for the participants

\begin{tabular}{ll}
\hline Relationship with: & Achievement motivation: \\
\hline Emotional & 0.33 \\
Social & 0.31 \\
Behavioral & 0.17 \\
Self-confidence & 0.44 \\
Confidence of the others & 0.37 \\
Determination and Perseverance & 0.50 \\
Cognitive & 0.36 \\
Academic & 0.51 \\
Moral & 0.40 \\
\hline The perceived self-efficacy & 0.55 \\
\hline
\end{tabular}

The Table 3 indicates that the relationship between the perceived self-efficacy and its dimensions on the one hand and the achievement motivation on the other hand for the participants may be classified as the following:

A. It has a very weak force and a positive direction (proportional) of the statistical significance at the significance level $(\alpha=0.05)$ : between the perceived self-efficacy dimension (behavioral) on the one hand and the achievement motivation on the other hand.

B. It has a weak force and a positive direction (proportional) of the statistical significance at the significance level $(\alpha=0.05)$ : between the dimensions of the perceived self-efficacy dimensions (emotional, social, self-confidence, the confidence of others, cognitive, moral) on the one hand and between the achievement motivation on the other hand.

C. It has a median force and a positive direction (proportional) of statistical significant at the significance level $(\alpha=0.05)$ : between the perceived self-efficacy and its two dimensions (determination and perseverance, academic) and the achievement motivation. This may explain the importance of determination and perseverance, academic efficiency in achieving success and academic attainment more than others. This result agrees with the result of Bandura's and Wood's study (1989) and Landine's and Stewart's study (1998) which indicate that there is a positive relationship between the perceived self- efficacy and the achievement motivation; where the correlation between these two variables can be interpreted that the perceived self-efficacy influence on the behavior, and the performance motivation.

\section{Conclusion}

The results indicated to the high levels of perceived self-efficacy and achievement motivation among students. Depending on these results it is recommended to make a training course for students to employ and exploite the achievement motivation and the high perceived self-efficacy in their academic success and excellence. Also encourage conducting future studies that affect on the perceived self-efficacy is fairly family, socialization, academic environment, and the other samples.

\section{Acknowledgments}

This is a research project that was supported by a grant from deanship of scientific research, Prince Sattam bin Abdul Aziz University.

\section{References}

Ababneh, M. F. (1999). The Level of Achievement Motivation among Yarmouk University Students and its Relationship to some personality Traits (Master Thesis). Yarmouk University, Irbid, Jordan.

Abu Allam, R. M. (2004). Learning its Basics and Applications. Amman, Dar Al Masirah.

Ammar, M. (1987). A Comparative Field Study about Achievement Motivation among psychology and philosophy Majors. Tunisian Journal for Educational Sciences, 12(16), 5-30. 
Assaqer, T. M. (2005). The Level of Moral Growth and Perceived self-Efficacy among a Sample of Yarmouk University Students in light of some variables (Unpublished Master Thesis). Yarmouk University, Irbid, Jordan.

Attawwab, S. M. (1990). The Integration of Achievement Motivation level, Intellegence and Sex effect on Learning among Male and Female Students at United Arab Emirates University. Journal of College of Education at United Arab Emirates University, 1(5), 16-49.

Azzyat, F. M. (2001). Cognitive Psychology, Part Two, Introductions, Models, Theories (1st ed.). Cairo: Dar Alnasher LILJAMI'AT.

Bandura, A. (1986). Social Foundation of Thought and Action Engle Wood Cliffs Prentice Hall. Dissertation Abstract International, 56(4), 123-129.

Bandura, A. (1987). Perceived Self-Efficacy and Pain Control: Opioid and Nonopioid Mcahanish. Journal of Personality and Social Psychology, 53(3), 563-571. https://doi.org/10.1037/0022-3514.53.3.563

Bandura, A., \& Wood, R. (1989). Effect of perceived Controllability and performance standards on self-Regulation of complex Decision Making and Self Efficacy. Journal of Personality and Social Psychology, 56(5), 805-814. https://doi.org/10.1037/0022-3514.56.5.805

Deci, E. (1989). Self-Determination in a Work Organization. Journal of Applied psychology, 74, 580-590. https://doi.org/10.1037/0021-9010.74.4.580

Dunham, R. B. (1973). Achievement motivation as predictive of academic performance: A multivariate analysis. The Journal of Educational Research, 67(2), 70-73. https://doi.org/10.1080/00220671.1973.10884566

Hamdi, N., \& Dawood, N. (2000). The relationship of Perceived self-efficacy to Depression and Tension among The Educational Sciences faculty Students in the University of Jordan. Educational Sciences Studies Journal, 27(1), 118-131.

Hanover, B. (2000). Investigation of the role of the gender in developing self-Efficacy. In The Development Social psychology of Gender (pp. 177-206). N.J. Lawrence-Errlbaum Associates.

Hassn, H. A. (1998). Achievement Psychology-Cognitive and Temperamental Features of Achieving personality. Cairo: Dar Al Nahdhah Library.

Harter, S. (1983). Developmental Perspective on the Self System. In P. Mussen (Ed.), Hand book of child psychology socialization, personality and Social development. Ny: John Wieley \& Sons.

Khalifah, A. (2000). Achievement Motivation. Cairo, Dar Ghareeb for Printing and Publishing.

Landine, J., \& Stewart, J. (1998). Relationship between Meta-cognition, Motivation, locus of control, Self-Efficacy, and Academic Achievement. Canadian Journal of Counseling, 32(3).

Lent, R., Brown, D., \& Larkin, C. (1984). Relation of Self-Efficacy Expectation to Academic Achievement and persistence. Journal of Counseling Psychology, 31(3), 356-362. https://doi.org/10.1037/0022-0167.31.3.356

Maddux, J., \& Lewis, J. (1995). Self-Efficacy, and adjustment. Basic principles and Issues. In Maddux (Ed.), Self-Efficacy Adaptation, and adjustment. Plenum Press. https://doi.org/10.1007/978-1-4419-6868-5_2

Nashawati, A. (2003). Educational Psychology (4th ed.). Irbid, Jordan: Dar Alforgan.

Pajares, F. (1999). Self-Efficacy, Motivation Constructs, and Mathematics Performance of Entering Middle School Students. Journal of Educational Psychology, 24(2), 124-139. https://doi.org/10.1006/ceps.1998.0991

Schunk, D. H. (1986). Self-Efficacy and skill development influence of task strategies and attribution. Journal of Educational Research, 79(1), 238-244. https://doi.org/10.1080/00220671.1986.10885684

Zahran, H. A. (2003). Studies in Psychological Health and psychological Counseling (1st ed.). Cairo: Alem Al Kotob. 


\section{Appendix A}

\section{Definitions of Terms.}

Perceived Self-efficacy: is the individual's belief and confidence in its potential and abilities and information that enables him to achieve a satisfactory level of balance, and that a positive perception of self-efficiency enables the individual to control events and to achieve a good level of achievement, determine the effort and the way of thinking and compatibility with environmental demands, control over any possible tension, and procedurally identify with total degree obtained inspected to tool of used perceived self-efficacy.

Achievement Motivation: it is the feeling of joy that follows the unique performance of a task associated to make the effort to achieve the success, and the satisfaction of biological, psychological and social needs which remove stress and achieve balance and harmony of the individual with the external and internal environment. It may arise and grow by comparing the individual him/herself within the internal personal standards of achievement, and comparing the individual to the others within the excellent standards in a particular situation. It procedurally identify with total degree obtained inspected to the achievement motivation tool used by the researcher.

Parallel Program Students: they are the students who study in the evening and pay more money to the university. They are usually government employees and older than their colleagues.

\section{Appendix B}

Dear participant:

You are kindly requested to reply to the items of the questionnaire on "Perceived Self-Efficacy and its Relationship to the Achievement Motivation among Parallel Students Program at Sattam Bin Abdul Aziz University". The information will be used for research purposes only. Read carefully and put a tick $(\checkmark)$ in front of your choice.

Ahmad Hasan Harahsheh

\begin{tabular}{|c|c|c|c|c|c|c|}
\hline Dimension & Rank & $\begin{array}{l}\text { No. of } \\
\text { item }\end{array}$ & Perceived self-efficacy & $\begin{array}{l}\text { Arithmetic } \\
\text { average }\end{array}$ & $\begin{array}{l}\text { Standard } \\
\text { deviation }\end{array}$ & Level \\
\hline \multirow[t]{8}{*}{ Emotional } & 1 & 4 & $\begin{array}{l}\text { - I think that I am calm and balanced } \\
\text { personal. }\end{array}$ & 4.18 & 0.88 & High \\
\hline & 2 & 5 & $\begin{array}{l}\text { - I effectively participate in the joy and } \\
\text { joking. }\end{array}$ & 4.12 & 0.91 & High \\
\hline & 3 & 8 & - I relax when I want that. & 3.94 & 1.01 & High \\
\hline & 4 & 3 & - I deal with the pressures of life well. & 3.90 & 0.89 & High \\
\hline & 5 & 7 & $\begin{array}{l}\text { - I overcome my hatred for some people. } \\
\text { - I get rid of the negative thoughts easily. }\end{array}$ & 3.82 & 1.06 & High \\
\hline & 6 & 2 & $\begin{array}{l}\text { - I control my feeling when I'm anxious. } \\
\text { - I control my behavior while I am angry. }\end{array}$ & 3.75 & 0.93 & High \\
\hline & 7 & 1 & & 3.68 & 0.87 & High \\
\hline & 8 & 6 & & 3.66 & 1.00 & High \\
\hline \multirow[t]{6}{*}{ Social } & 1 & 14 & $\begin{array}{l}\text { - I maintain the friendly relations with } \\
\text { relatives. }\end{array}$ & 4.49 & 0.68 & High \\
\hline & 2 & 15 & - I get others' love easily. & 4.24 & 0.75 & High \\
\hline & 3 & 10 & - I disscuss with others easily. & 4.20 & 0.85 & High \\
\hline & 4 & 16 & $\begin{array}{l}\text { - I advice all of them because they } \\
\text { adeserve. }\end{array}$ & 4.20 & 0.97 & High \\
\hline & 5 & 9 & & 4.20 & 0.84 & High \\
\hline & 6 & 11 & $\begin{array}{l}\text { - I find appreciation and admiration of } \\
\text { my colleagues. } \\
\text { - I have the ability to make friendships. } \\
\text { - friends telling me about their problems. }\end{array}$ & 4.16 & 0.91 & High \\
\hline
\end{tabular}




\begin{tabular}{|c|c|c|c|c|c|c|}
\hline & 7 & 12 & - I forgive others who abuse me. & 3.91 & 1.04 & High \\
\hline & 8 & 13 & & 3.80 & 0.99 & High \\
\hline \multirow[t]{9}{*}{ Behavioral } & 1 & 23 & $\begin{array}{l}\text { - I flout and underestimate the thoughts } \\
\text { of others (inverse). }\end{array}$ & 4.40 & 0.96 & High \\
\hline & 2 & 24 & - I eat food gluttonously (inverse). & 4.32 & 1.12 & High \\
\hline & 3 & 18 & - I immediately help others. & 4.28 & 0.84 & High \\
\hline & 4 & 21 & $\begin{array}{l}\text { - I quietly and politely express my } \\
\text { thoughts. }\end{array}$ & 4.28 & 0.76 & High \\
\hline & 5 & 22 & $\begin{array}{l}\text { - I talk arrogantly and disdainfully } \\
\text { (inverse). }\end{array}$ & 4.04 & 1.28 & High \\
\hline & 6 & 19 & $\begin{array}{l}\text { - I criticize the others by a civilized } \\
\text { manner. }\end{array}$ & 3.76 & 1.06 & High \\
\hline & 7 & 17 & $\begin{array}{l}\text { - I insult the others who who abuse me } \\
\text { (inverse). }\end{array}$ & 3.71 & 1.16 & High \\
\hline & 8 & 25 & $\begin{array}{l}\text { - I raise my voice when I'm angry } \\
\text { (inverse). }\end{array}$ & 3.03 & 1.34 & Median \\
\hline & 9 & 20 & $\begin{array}{l}\text { - I refuse others' behavior that refuse my } \\
\text { thoughts (inverse). }\end{array}$ & 2.76 & 1.13 & Median \\
\hline \multirow[t]{9}{*}{ Self-confidence } & 1 & 32 & $\begin{array}{l}\text { - I think that I will be successful in the } \\
\text { future. }\end{array}$ & 4.36 & 0.76 & High \\
\hline & 2 & 33 & $\begin{array}{l}\text { - I rely on myself in decisions making. } \\
\text { - I am proud of myself, my strength, and }\end{array}$ & 4.26 & 0.81 & High \\
\hline & 3 & 29 & my weekness. & 4.15 & 1.02 & High \\
\hline & 4 & 26 & $\begin{array}{l}\text { - I think I was able to do a lot of things. } \\
\text { - I make successful decisions easily. }\end{array}$ & 4.10 & 0.96 & High \\
\hline & 5 & 34 & $\begin{array}{l}\text { - I make my decision without hesitation. } \\
\text { - I overcome the difficulties easily. }\end{array}$ & 3.94 & 0.94 & High \\
\hline & 6 & 27 & - I think that my decisions far from & 3.73 & 0.95 & High \\
\hline & 7 & 31 & reality (inverse). & 3.63 & 0.87 & High \\
\hline & 8 & 28 & - I ask others to me help (inverse). & 3.30 & 1.16 & Median \\
\hline & 9 & 30 & & 2.87 & 1.04 & Median \\
\hline \multirow[t]{7}{*}{$\begin{array}{l}\text { Confidence of the } \\
\text { others }\end{array}$} & 1 & 38 & $\begin{array}{l}\text { - I get the respect of the others who I } \\
\text { deal. }\end{array}$ & 4.46 & 0.70 & High \\
\hline & 2 & 35 & - Others trust my ability. & 4.06 & 0.76 & High \\
\hline & 3 & 41 & - My friends ask me to help them. & 4.05 & 0.79 & High \\
\hline & 4 & 39 & - Others trust my view. & 4.01 & 0.86 & High \\
\hline & 5 & 40 & $\begin{array}{l}\text { - Others consider my presence and my } \\
\text { absence are alike (inverse). }\end{array}$ & 3.88 & 1.30 & High \\
\hline & 6 & 36 & - I can persuade others to my view. & 3.86 & 0.91 & High \\
\hline & 7 & 37 & $\begin{array}{l}\text { - I find flout and underestimate of the } \\
\text { others (inverse). }\end{array}$ & 3.81 & 1.15 & High \\
\hline \multirow[t]{4}{*}{$\begin{array}{l}\text { Determination } \\
\text { Perseverance }\end{array}$} & 1 & 43 & $\begin{array}{l}\text { - I try more than once to achieve my } \\
\text { goal. }\end{array}$ & 4.29 & 0.80 & High \\
\hline & 2 & 46 & $\begin{array}{l}\text { - I try to be patient to reach to the desired } \\
\text { goal. }\end{array}$ & 4.25 & 0.91 & High \\
\hline & 3 & 42 & - I perform the work which I plan. & 4.23 & 0.81 & High \\
\hline & 4 & 47 & $\begin{array}{l}\text { - I focus on the work which needs to long } \\
\text { time. }\end{array}$ & 4.15 & 0.96 & High \\
\hline
\end{tabular}




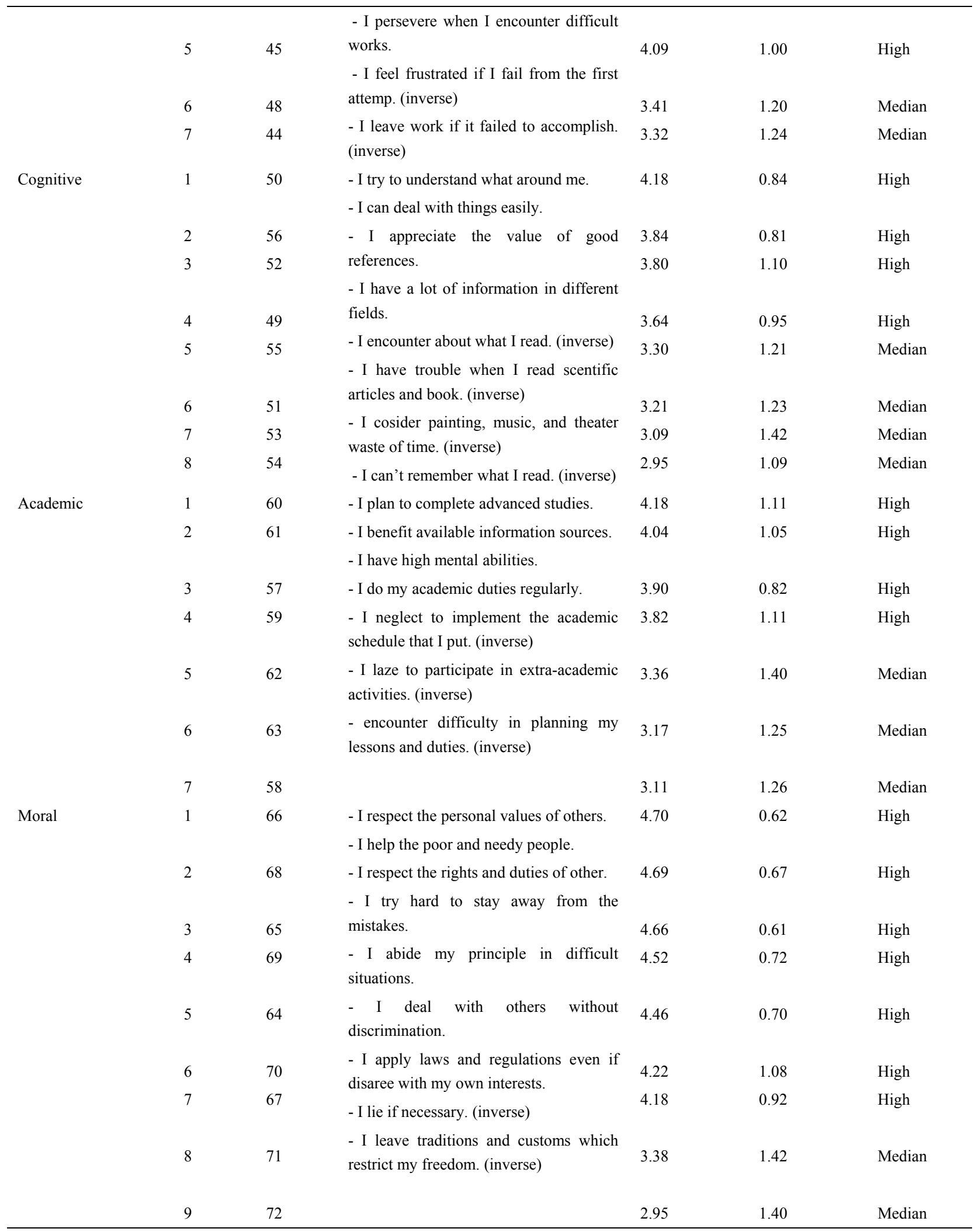

\section{Copyrights}

Copyright for this article is retained by the author(s), with first publication rights granted to the journal.

This is an open-access article distributed under the terms and conditions of the Creative Commons Attribution license (http://creativecommons.org/licenses/by/4.0/). 